\title{
Article \\ Comparative Analysis of Gasification and Adiabatic Digestion of Corn for Practical Implementation in Conventional Gas Turbines
}

\author{
Milana Guteša Božo ${ }^{1, *}$ and Agustin Valera-Medina ${ }^{2}(\mathbb{0}$ \\ 1 Termoinžinjering d.o.o, Research and Development Department, Dragice Pravice 52, 23000 Zrenjanin, Serbia \\ 2 Cardiff School of Engineering, Queen's Buildings, 14-17 The Parade, Cardiff CF24 3AA, Wales, UK; \\ valeramedinaA1@cardiff.ac.uk \\ * Correspondence: milanagutesabozo@termoinzinjering.rs
}

Citation: Guteša Božo, M.; Valera-Medina, A. Comparative Analysis of Gasification and Adiabatic Digestion of Corn for Practical Implementation in Conventional Gas Turbines. Gases 2021, 1, 92-105. https://doi.org/ $10.3390 /$ gases 1020008

Academic Editor: Ben J. Anthony

Received: 8 April 2021

Accepted: 21 May 2021

Published: 27 May 2021

Publisher's Note: MDPI stays neutral with regard to jurisdictional claims in published maps and institutional affiliations.

Copyright: (c) 2021 by the authors. Licensee MDPI, Basel, Switzerland. This article is an open access article distributed under the terms and conditions of the Creative Commons Attribution (CC BY) license (https:// creativecommons.org/licenses/by/ $4.0 /)$.

\begin{abstract}
Clean, more responsible energy production in gas turbine power plants is a challenge. Interestingly, various alternative sources could be found in agricultural locations with great potential of being transformed from agricultural waste to energy. Corn cob gasification gas could be successfully implemented in gas turbines through co-firing with natural gas. Concurrently, agricultural biogas could also be employed for such a purpose. The technology could be implemented in locations such as Vojvodina, Serbia, which is an agricultural region with great potential for producing biogas from agricultural waste. Therefore, this paper approaches the practical implementation of gas produced by adiabatic corn digestion with $\mathrm{CO}_{2}$ recirculation. Five different cases were assessed. The results are compared to previous analyses that used co-firing of the corn cob gasification gas in representative gas turbine systems. Impacts of the fuel composition on the characteristics of combustion were analyzed using CHEMKIN PRO with GRI-Mech 3.0. Impacts of fuel quality on the power plant performance were analyzed through calculations with a numerical model based on a Brayton cycle of 3.9 MW power output. The application shows acceptable values during co-firing with natural gas without modification of the overall system, with better outlet parameters compared to pure corn gasification gas.
\end{abstract}

Keywords: gas turbine; gasification; adiabatic digestion; corn; bioenergy; simulation; biomass

\section{Introduction}

The utilization of biomass as an energy source is inefficient in many developing agricultural regions that intend to use it as alternative energy source [1]. However, biomass can provide an economically sustainable energy source as long as it is recovered from either industrial or agricultural waste. Further, advantages can also be achieved through the local reduction of fossil-based sources, with great positive impact in countries with significant energy dependance on fossil imports.

Currently, biomass power cycles are showing high potential when implemented in gas turbine power plants [2-4]. Even though their significant potentials, combustors designs for these biogases have to overcome irregularities of combusting biogas blends with lower heating value (which is about $30 \%$ of that of natural gas) [5], combustion instabilities and corrosion effects. Operating irregularities could be solved by appropriate modifications followed by certain stability passive methodologies [6]. In cases where the heating value of the biogas is significantly different compared to natural gas, operation irregularities are solved by partial fuel substitution implementing co-firing of alternative gas with natural gas [7-9]. It is known that decreased methane amounts in biogases can cause off-design operation of turbine systems [10]; therefore, the practical implementation of these biogases can be only carried out through the proper acknowledgement of thermodynamic and operational impacts that could occur in such devices. These impacts can be predicted 
by mathematical models [11,12], which are highly flexible and have a wide range of stability parameters.

As shown in previous analyses [12], the practical implementation of biomass gasification is a promising way of implementing biomass as an alternative fuel in gas turbine facilities [1,13], with great potential of reduction of greenhouse gases (GHGs). Biomass obtained from waste such as corn cobs is also a growing trend in corn producing regions since corn represents one of the most produced agricultural products in the world. Despite its low heating value, it has been shown that up to $40 \%$ of the corn cob gasification gas could be co-fired with natural gas with promising outlet parameters [12]. Therefore, this source presents a path to development sustainable solutions with the improvement of the local environment.

On the other hand, gas from gasification has low methane content, hence it is a low calorific gas. With these characteristics, it is not suitable for its direct use in gas turbine plants. However, by changing the gas production path from gasification to adiabatic digestion, it is possible to obtain a product gas with significant increase of methane share $(\sim 60 \%)$ [14]. This trend has been demonstrated from other digestors, which usually produce product gases that contain $55 \%$ to $65 \%$ methane, $35 \%$ to $45 \%$ carbon dioxide and $<1 \%$ nitrogen [15]. Therefore, such a biogas would be of medium calorific value, and it could be possible to obtain better outlet parameters during power production [16,17]. Therefore, anaerobic digestion of biomass is a promising and proven alternative treatment of biodegradable waste [18]. Further, anaerobic digestion gas production is a technology that supports energy-efficiency improvement and environment protection with significant advantages compared to other forms of bioenergy $[19,20]$. Moreover, fertilizers can also be a by-product of this gas production path; thus, digestion can produce fuel and fertilizers whilst increasing its sustainability appraisal [15].

Implementation of anaerobic digestion gas in the micro-gas turbine in combination with waste heat application in adiabatic digester has shown great potential for industrial power plants [21]. Mixing of the anaerobic digestion gas with natural gas in a combined heat and power (CHP) cycle showed exergy efficiency of 50.5\% with $50 \%$ anaerobic digestion gas in the fuel mixture [22]. Energy, exergy, environmental and economic analyses showed that optimal ratio of anaerobic biogas and natural gas is 0.55 in a dual fuel gas turbine cycle would be the preferred option $[23,24]$. Similarly, a CHP facility that combines a $30 \mathrm{MW}$ gas turbine cycle, steam generator and anaerobic digestor has delivered the exergy efficiency $46.94 \%$ with $100 \%$ biogas. This number can be compared to cases where pure natural gas was employed, giving exergy efficiencies of $50.64 \%$ [22,25]. Further, related studies that approach non-premixed combustion of natural gas and biogas in micro combustors have shown that despite a decrease in methane, the right combination of swirl number and fuel injector diameters can enable adequate performance comparable to natural gas cycles whilst delivering power at low NO emissions [26,27]. New ideas of implementing anaerobic digestion gas in the gas turbine cycle that are reflected in combining gas turbine cycles are also tangible whilst combining the gas turbine cycle with $\mathrm{CO}_{2}$ recirculation and oxy-fuel combustion in two zone models with potential for carbon capture and storage (CCS) [28], micro turbine coupled with Permanent Magnet Synchronous Generators (PMSG) [29] and combined gas turbines that employ supercritical $\mathrm{CO}_{2}$ with cooling at the inlet of the compressor [30]. All the above analyses show high possibility of implementation biomass anaerobic digestion gas fueling with great potential of decreasing both emissions and use of fossil fuels.

Therefore, this analysis presents predictions of several parameters and practical implementation of corn cob digestion gas as a substitute of natural gas for gas turbine power plants. Results provide valuable information for implementation of this alternative source. The study is complemented by a comparison with previous studies that addressed the use of gasification, thus denoting the implications of using different product gases from the same agricultural feedstock. Through this study, it is shown that corn cob adiabatic digestion gas could be applied in a conventional energy production system with appropriate 
combination of minimal fuel system and gas turbine modifications for the high share of CCADG in the fuel and with significant outlet power and efficiency values.

\section{Materials and Methods}

\subsection{Numerical Model of a Physical Cycle}

In previous analyses, a bespoke model of an industrial gas turbine was employed to recognize and understand the possible changes in gas turbine cycle performance when different gas blends of corn gasification are employed [12]. The developed numerical model was calibrated and validated in previous studies against industrial systems with errors no greater than $2 \%$ [31,32]. The model is based on an integral cycle approach, considering a non-adiabatic expansion and inter-cooling across the turbine [33]. Development of the model, calibration and validation are presented elsewhere [12,34].

\subsection{Gas Combustion Modeling}

For determination of the composition of the combustion gases for their application in the numerical model, Table 1, analyses were done via CHEMKIN-PRO and the reaction chemical model GRI-Mech 3.0 [35-37]. Results were used in the numerical simulation of a gas turbine fed with corn gasification gas [12], and corn adiabatic digestion gas, Table 1.

Table 1. Gas composition obtained by simulation of downdraft CCGG [1] and CCADG [14,18].

\begin{tabular}{cccc}
\hline & Dry CCGG & Wet CCGG & CCADG \\
\hline $\mathrm{N}_{2}[\mathrm{vol} \%]$ & 43.01 & 47.09 & $0-5$ \\
$\mathrm{CO}_{2}[\mathrm{vol} \%]$ & 10.42 & 11.41 & $15-60$ \\
$\mathrm{CO}[\mathrm{vol} \%]$ & 19.40 & 21.24 & - \\
$\mathrm{H}_{2}[\mathrm{vol} \%]$ & 16.67 & 18.26 & Traces \\
$\mathrm{CH}_{4}{ }^{*}[\mathrm{vol} \%]$ & 1.83 & 2.00 & $40-75$ \\
$\mathrm{H}_{2} \mathrm{O}[\mathrm{vol} \%]$ & 8.70 & - & $1-5 \%$ \\
$\mathrm{H}_{2} \mathrm{~S}[\mathrm{vol} \%]$ & - & - & - \\
$\mathrm{O}_{2}[\mathrm{vol} \%]$ & - & - & $<2$ \\
$\mathrm{LHV}\left[\mathrm{MJ} / \mathrm{m}^{3}\right]$ & 4.90 & 5.37 & 21.48 \\
$\mathrm{LHV}[\mathrm{MJ} / \mathrm{kg}]$ & 5.26 & 5.77 & 30.00 \\
\hline
\end{tabular}

${ }^{*}$ Fixed methane share in the gas.

Combustion simulations were performed using a hybrid of Perfectly Stirred ReactorsPlug Flow Reactor (PSR-PFR). This network assumes adequate mixing and flow characteristics representative of swirling gas turbine combustors [38]. PSR-PFR consists of two clusters; the first section is comprised of three distinct zones, namely a mixing zone for partial premixing of fuel, a flame region directly connected to the former and the central recirculation zone (CRZ) for combustion products recirculation [31,32]. Recirculation rates in PSR are approximated to $20 \%$ of the combustion products [39-41]. The second cluster is a PFR (Plug Flow Reactor) for post-flame operation along a $0.1 \mathrm{~m}$ duct [42], Figure 1.

\subsection{Fuel Selection}

For this work, two types of corn gases were considered: (1) gas from corn cob gasification (CCGG) obtained experimentally [1], and (2) corn adiabatic digestion gas (CCADG) whose composition is based on an approximation of mean values from facilities where corn adiabatic digestion gas has been produced CCADG $[14,18]$. The corn cob gasified gas has a low share of methane $(\sim 2 \%)$ and, therefore, low calorific value, Table 1 . Further, analyses were done using dry conditions. Simultaneously, the analyzed adiabatic digestion gas was considered with a high methane share $(60 \%)$ and $40 \%$ of carbon dioxide, Table 1 CCADG. 
(a)
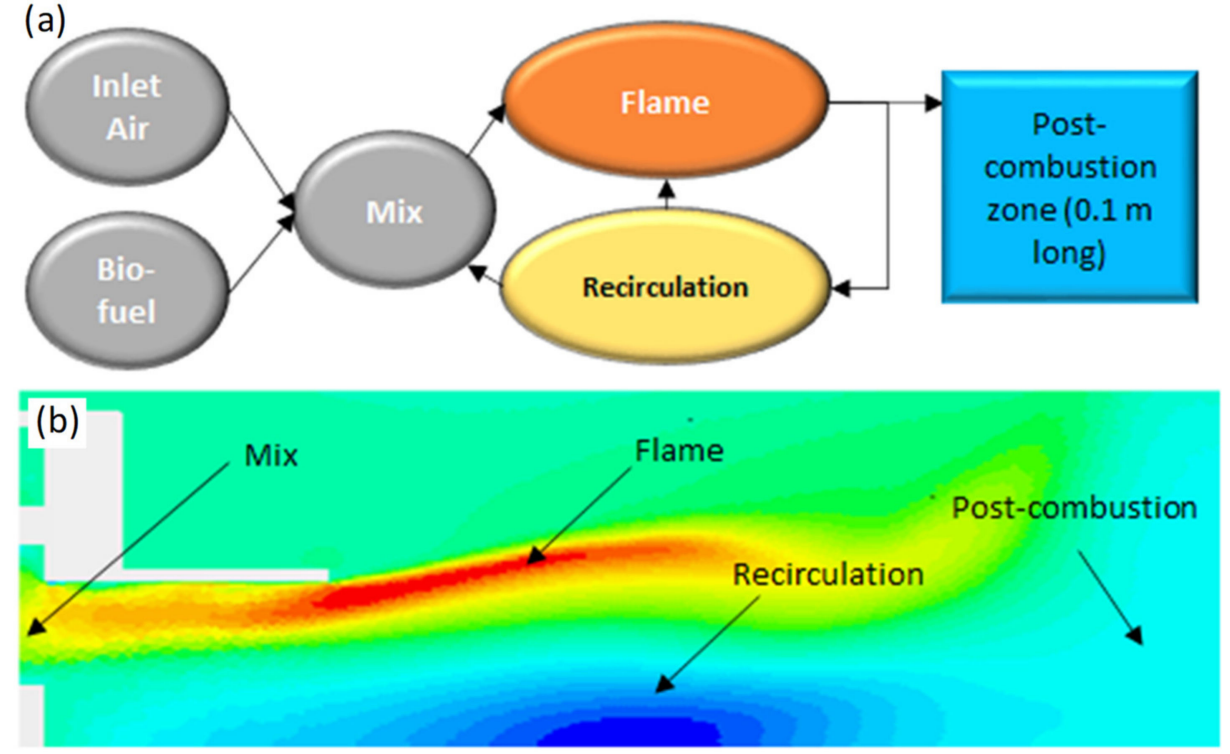

Figure 1. (a) PSR-PFR Schematic; (b) Model flame.

The CCGG gas delivers a Wobbe Index (WI) difference of $80 \%$ when compared to natural gas, while for CCADG, this difference is only $44 \%$. For cases where the WI difference is above $50 \%$, these gases can only be used in conventional gas turbine cycles only through co-firing with natural gas [43]. In previous analyses [12], CCGG was co-fired with natural gas. Analyses were done for fuel blends with different CCGG ratios from $0 \%$ to $40 \%$ of CCGG in co-firing modes with natural gas. Results from that study are compared to the performance of corn adiabatic digestion gas in the same conventional gas turbine [12]. Five fuel blends with different gas ratios were also defined with increments of $10 \%$ between cases. The selected fuel blends are presented in Tables 2 and 3, respectively.

Table 2. The selected fuel blends composition (CCGG and natural gas).

\begin{tabular}{cccccc}
\hline $\begin{array}{c}\text { Composition } \\
\text { [Molar Fraction] }\end{array}$ & $\begin{array}{c}\mathbf{0} \% \\
\text { CCGG }\end{array}$ & $\begin{array}{c}\mathbf{1 0} \% \\
\text { CCGG }\end{array}$ & $\begin{array}{c}\mathbf{2 0} \% \\
\text { CCGG }\end{array}$ & $\begin{array}{c}\mathbf{3 0} \% \\
\text { CCGG }\end{array}$ & $\begin{array}{c}\mathbf{4 0} \% \\
\text { CCGG }\end{array}$ \\
\hline $\mathrm{CH}_{4}$ & 0.9247 & 0.8342 & 0.7438 & 0.6533 & 0.5628 \\
$\mathrm{C}_{2} \mathrm{H}_{6}$ & 0.0350 & 0.0315 & 0.0280 & 0.0245 & 0.0210 \\
$\mathrm{C}_{3} \mathrm{H}_{8}$ & 0.0132 & 0.0119 & 0.0106 & 0.0092 & 0.0079 \\
$\mathrm{C}_{4} \mathrm{H}_{10}$ & 0.0022 & 0.0019 & 0.0018 & 0.0015 & 0.0013 \\
$\mathrm{C}_{5} \mathrm{H}_{12}$ & 0.0006 & 0.0005 & 0.0006 & 0.0004 & 0.0004 \\
$\mathrm{~N}_{2}$ & 0.0175 & 0.0588 & 0.1000 & 0.1413 & 0.1825 \\
$\mathrm{H}_{2}$ & 0.0000 & 0.0167 & 0.0333 & 0.0500 & 0.0667 \\
$\mathrm{CO}$ & 0.0000 & 0.0194 & 0.0388 & 0.0582 & 0.0776 \\
$\mathrm{H}_{2} \mathrm{O}$ & 0.0000 & 0.0087 & 0.0174 & 0.0261 & 0.0348 \\
$\mathrm{CO}_{2}$ & 0.0068 & 0.0165 & 0.0263 & 0.0360 & 0.0458 \\
\hline
\end{tabular}

Table 3. The selected fuel blends composition (CCADG and natural gas).

\begin{tabular}{cccccc}
\hline $\begin{array}{c}\text { Composition } \\
\text { [Molar Fraction] }\end{array}$ & $\begin{array}{c}\mathbf{0} \% \\
\text { CCADG }\end{array}$ & $\begin{array}{c}\mathbf{1 0 \%} \\
\text { CCADG }\end{array}$ & $\begin{array}{c}\mathbf{2 0 \%} \\
\text { CCADG }\end{array}$ & $\begin{array}{c}\mathbf{3 0} \% \\
\text { CCADG }\end{array}$ & $\begin{array}{c}\mathbf{4 0} \% \\
\text { CCADG }\end{array}$ \\
\hline $\mathrm{CH}_{4}$ & 0.9247 & 0.8922 & 0.8598 & 0.8273 & 0.7948 \\
$\mathrm{C}_{2} \mathrm{H}_{6}$ & 0.0350 & 0.0315 & 0.0280 & 0.0245 & 0.0210 \\
$\mathrm{C}_{3} \mathrm{H}_{8}$ & 0.0132 & 0.0119 & 0.0106 & 0.0092 & 0.0079 \\
$\mathrm{C}_{4} \mathrm{H}_{10}$ & 0.0022 & 0.0019 & 0.0018 & 0.0015 & 0.0013 \\
$\mathrm{C}_{5} \mathrm{H}_{12}$ & 0.0006 & 0.0005 & 0.0005 & 0.0004 & 0.0004 \\
$\mathrm{~N}_{2}$ & 0.0175 & 0.0158 & 0.0140 & 0.0123 & 0.0105 \\
$\mathrm{CO}_{2}$ & 0.0068 & 0.0461 & 0.0854 & 0.1248 & 0.1641 \\
\hline
\end{tabular}


The results from CHEMKIN-PRO were used in a gas turbine cycle simulation for prediction of the thermodynamic parameters of all cases The matrix of the corn cob combustion tests is given in Table 4, while the results for corn adiabatic digestion gas are presented in Table 5.

Table 4. Parameters at the combustion chamber inlet.

\begin{tabular}{cccccccc}
\hline Case & \multicolumn{2}{c}{ Inlet Data-Mass Flows and ER } & \multicolumn{3}{c}{ Pressure } \\
\hline & $\begin{array}{c}\mathbf{m}_{\text {fuel }} \\
{[\mathbf{k g} / \mathbf{s}]}\end{array}$ & $\begin{array}{c}\mathbf{m}_{\text {air }} \\
{[\mathbf{k g} / \mathbf{s}]}\end{array}$ & $\begin{array}{c}\text { ER CCGG } \\
{[-]}\end{array}$ & $\begin{array}{c}\text { ER CCADG } \\
{[-]}\end{array}$ & $\begin{array}{c}\mathbf{p}_{\text {fuel }} \\
{[\mathbf{b a r}]}\end{array}$ & $\begin{array}{c}\mathbf{p}_{\text {air }} \\
{[\mathbf{b a r}]}\end{array}$ & $\begin{array}{c}\mathbf{p}_{\text {combustion }} \\
{[\mathbf{b} \text { [bar] }}\end{array}$ \\
\hline 1 & 0.29 & 14.47 & 0.89 & 0.89 & 11.22 & 9.69 & 9.69 \\
2 & 0.29 & 14.47 & 0.78 & 0.81 & 11.22 & 9.69 & 9.69 \\
3 & 0.29 & 14.47 & 0.68 & 0.73 & 11.22 & 9.69 & 9.69 \\
4 & 0.29 & 14.47 & 0.58 & 0.67 & 11.22 & 9.69 & 9.69 \\
5 & 0.29 & 14.47 & 0.49 & 0.61 & 11.22 & 9.69 & 9.69 \\
\hline
\end{tabular}

Table 5. Types of manifold injection systems.

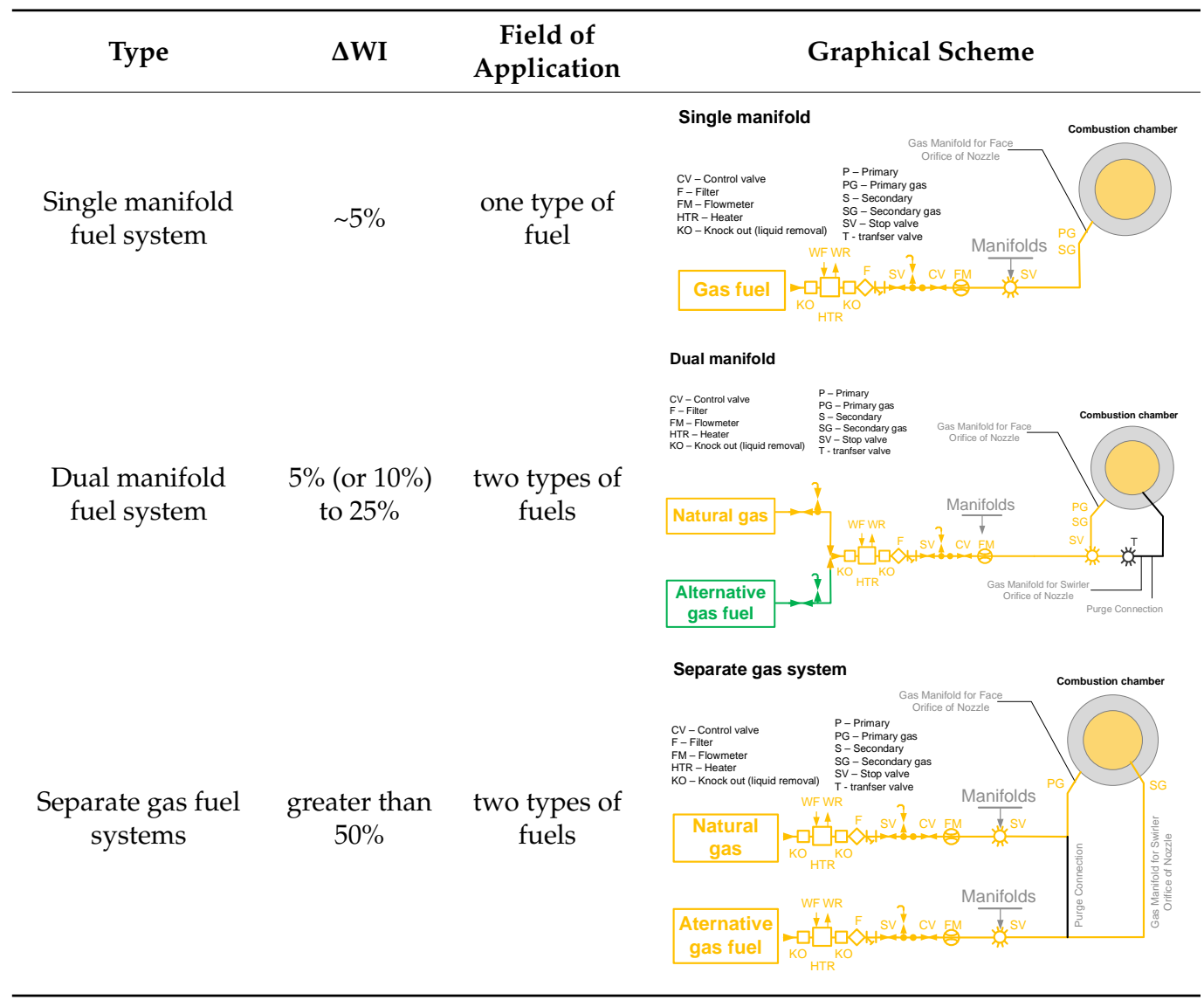

\subsection{Types of Manifold Injection}

Various manifold injection systems were considered for this analysis, i.e., single manifold, dual manifold and separate gas system [12]. In this analysis, all three systems were analyzed for the purpose of co-firing the alternative gas, either CCGG or CCADG, in a conventional gas turbine. Each of them has different purposes for various flow rate applications, Table 5.

For cases with a WI difference in a range from $25 \%$ to $50 \%$, both the dual manifold fuel system and separate gas systems could be employed [43]. However, other limitation criteria need to be analyzed before final selection, for example, the fuel propulsion, the maximum fuel velocity value $(20 \mathrm{~m} / \mathrm{s})$, etc. [44]. 


\section{Results and Discussion}

\subsection{Reaction Modeling}

Increase of CCGG share in the fuel blend decreases the adiabatic temperature $~ 7 \%$ for every $10 \%$ of the CCGG share, while an increase of CCADG share in the fuel mixture decreases the adiabatic temperature $\sim 5 \%$ for every $10 \%$ of the CCADG share, Figure 2.

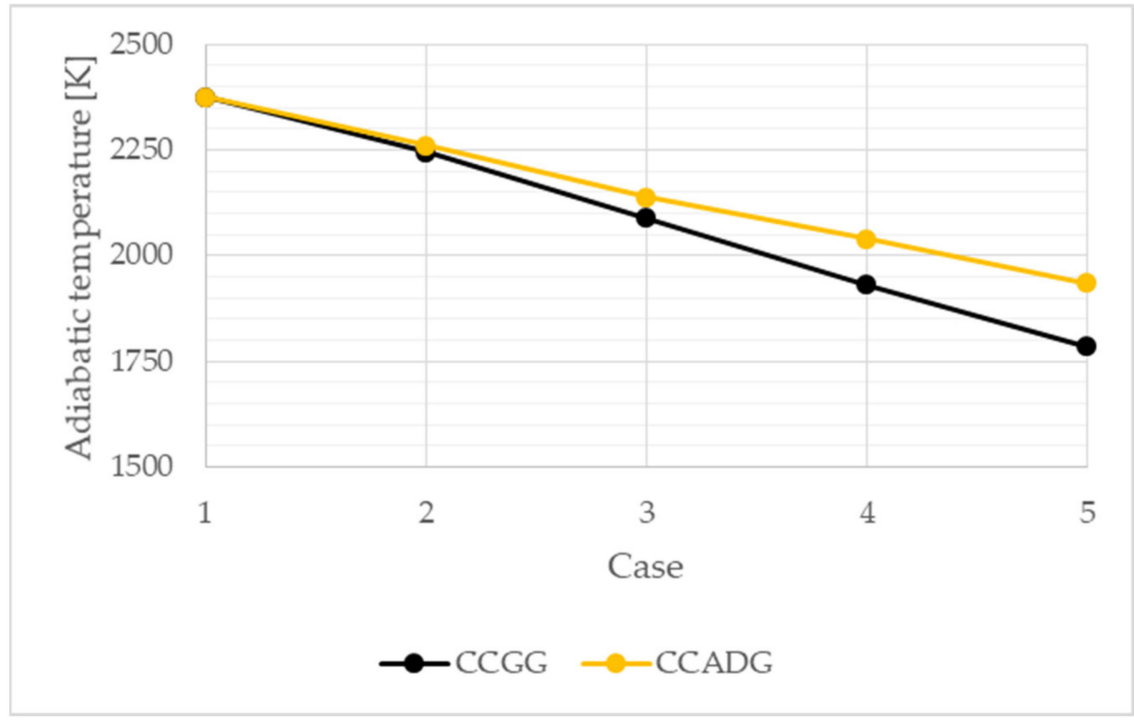

Figure 2. Change of adiabatic combustion temperature through composition change of fuel blend for the considered cases for corn cob gasification gas and corn adiabatic digestion gas.

In order to track the impacts of fuel quality changes, and therefore the gases in the combustion products, the following species were analyzed: oxygen, water vapor, carbon dioxide and nitrogen, Figures 7-10. All the analyses were done using the combustion products' specific heats [34].

By increasing of the share of the alternative gas in the fuel blend, in both fuel types, the oxygen share in the combustion products has increased, with a change in $\sim 30 \%$ for every $10 \%$ of the CCGG share and $26 \%$ for every $10 \%$ of the CCADG share, Figure 3 . The higher increase of the oxygen in the combustion products with CCGG is due to higher amounts of oxygen in such a fuel. In the case of the water vapor, there is a decrease in both cases with an increase of alternative gas share, Figure 4 , with $~ 14 \%$ for every $10 \%$ of the CCGG share and $\sim 9 \%$ for every $10 \%$ of the CCADG share. This is caused due to the lower number of hydrocarbons in the reactants. Higher content of water vapor in the combustion products of CCADG is due to the higher amount of the hydrocarbons in such a gas compared to CCGG.

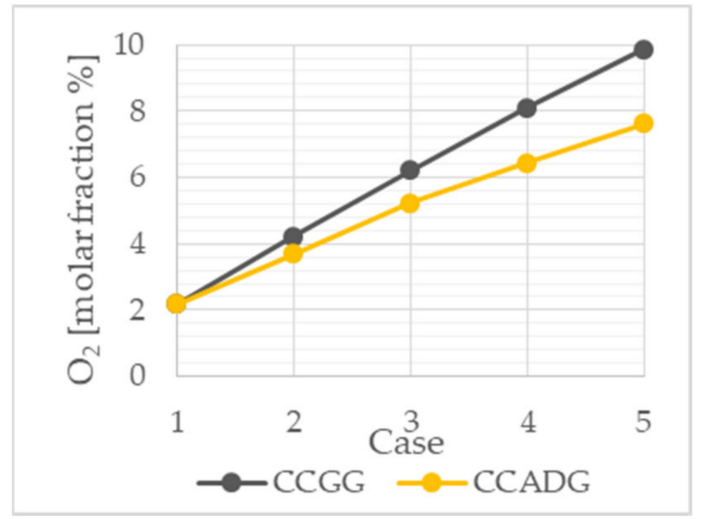

Figure 3. Change of oxygen content. 


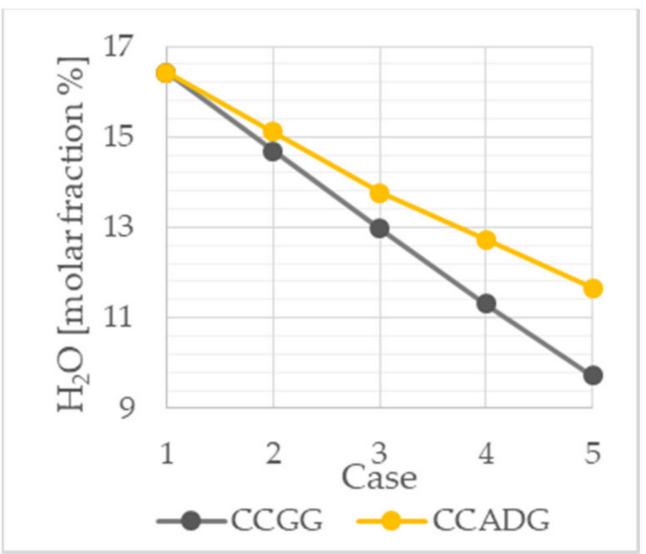

Figure 4. Change of water vapor content.

The carbon dioxide content in the combustion products was lower with an increase of the alternative gas share, with $\sim 11 \%$ for every $10 \%$ of the CCGG share and $\sim 4 \%$ for every $10 \%$ of the CCADG share. Regarding $\mathrm{CO}_{2}$ emissions, CCGG combustion showed a higher $\mathrm{CO}_{2}$ decrease due to its higher share of oxygen and lower share of methane, Figure 5. Finally, the nitrogen share content was higher with $~ 1 \%$ for every $10 \%$ of the CCGG share and $\sim 0.5 \%$ for every $10 \%$ of the CCADG share. As expected, the nitrogen increases in the combustion products with the higher share of the CCGG in the fuel and is almost double the value compared to the CCADG case, which is a consequence of the significantly high amount of nitrogen in the CCGG, Figure 6.

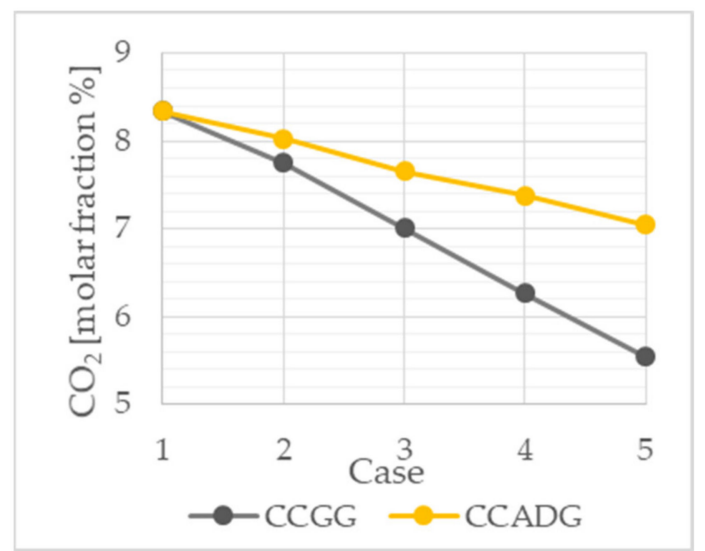

Figure 5. Change of carbon dioxide content.

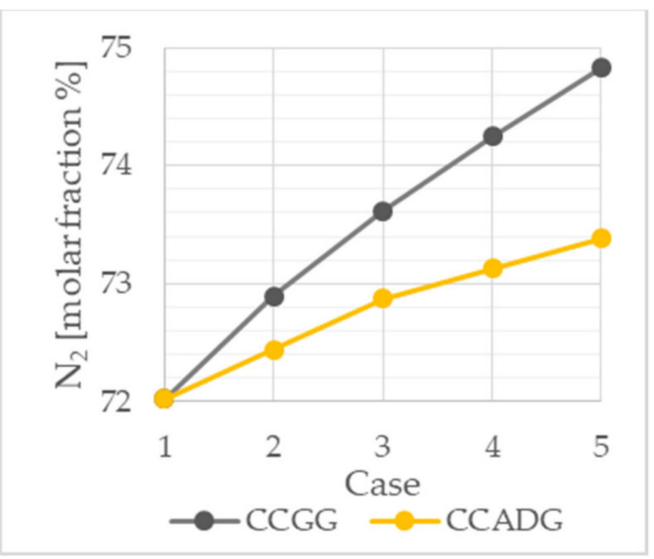

Figure 6. Change of nitrogen content. 
The variations of species such as of oxygen, water vapor, carbon dioxide and nitrogen were also assessed with respect to the adiabatic combustion temperature, Figures 7 and 8.

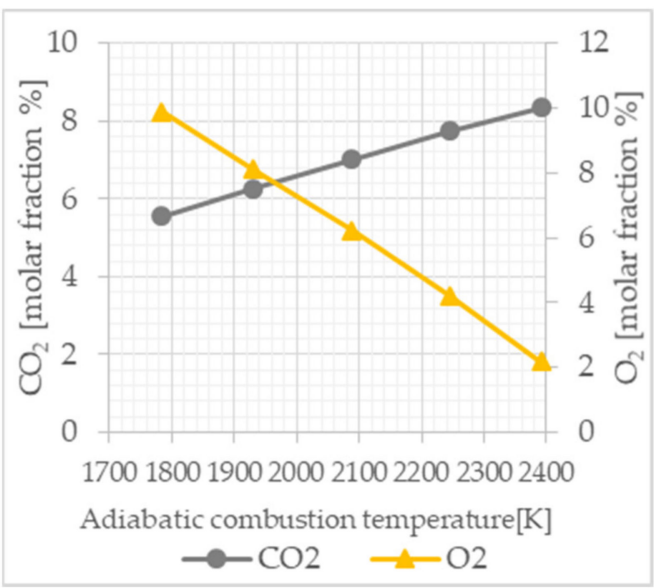

(a)

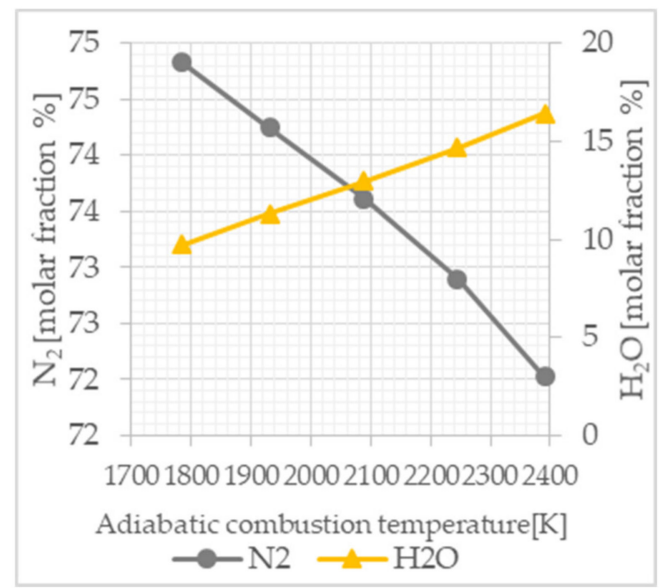

(b)

Figure 7. Composition change of the combustion products (a) carbon dioxide and oxygen and (b) nitrogen and water vapor as a function of adiabatic combustion temperature for CCGG combustion.

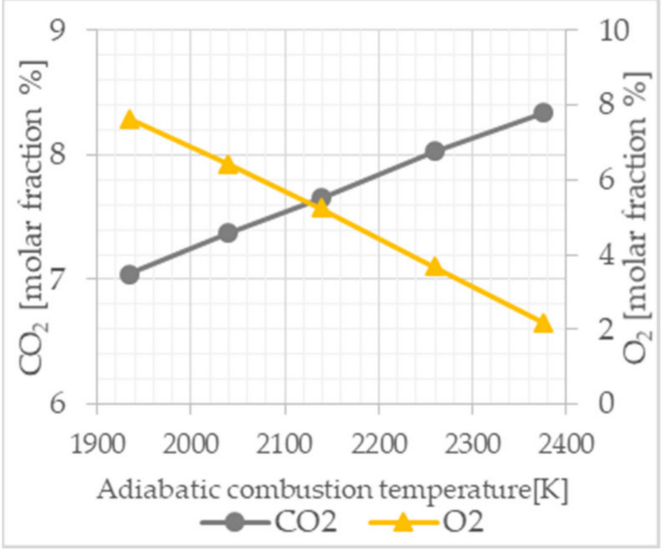

(a)

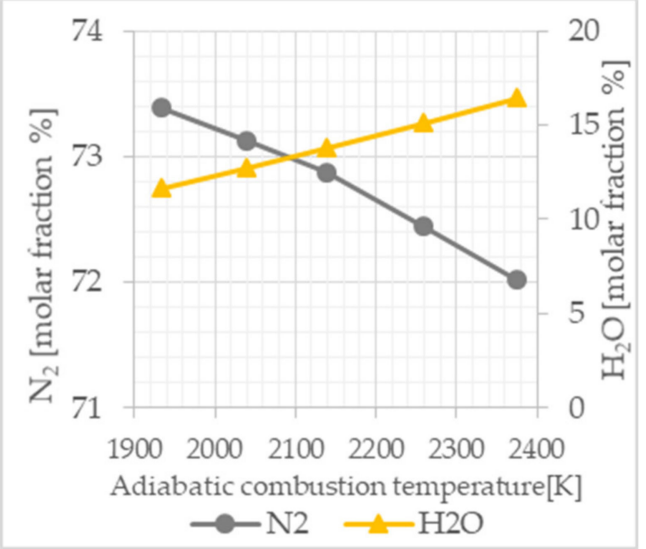

(b)

Figure 8. Composition change of the combustion products (a) carbon dioxide and oxygen and (b) nitrogen and water vapor as a function of adiabatic combustion temperature for CCADG combustion.

\subsection{Gas Turbine Simulation}

Further, the five different cases were analyzed for modeling purposes. The fuel flows in both scenarios, i.e., CCGG and CCADG, were calculated on the basis of the case with pure natural gas. The analyzed indicators of the gas turbine cycle were supplied heat, power, gas turbine plant efficiency and turbine outlet temperature. With higher content of the alternative gas in fuel mixture, there is a decrease of the specific heat value due to a decrease of heating value of the fuel, Figure 9. Simultaneously, the decrease of supplied heat is lower in the CCGG scenario due to lower heating values of CCGG compared to CCADG. For example, in case 5, the supplied heat value of CCADG is about $11 \%$ higher than CCGG. 


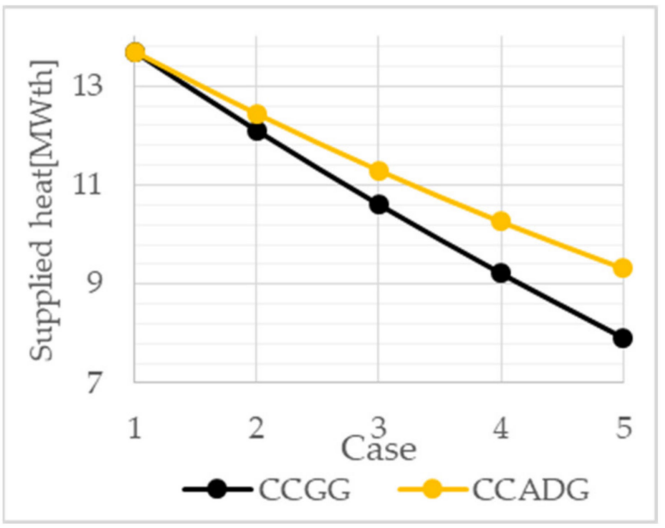

Figure 9. Change of supplied heat as a function of fuel composition for the considered scenarios with CCGG and CCADG, respectively.

Concurrently, a high share of alternative gas in the fuel mixture leads to lower power as a consequence of the lower fuel heating value, Figure 10. A decrease in power is also lower in the CCADG scenario, especially for cases with higher content of alternative gas share in the fuel blend. For example, in case 4 , the produced power in the CCADG scenario is $\sim 8 \%$ higher than in the scenario with CCGG, while for case 5 , the difference between both scenarios is $\sim 15 \%$.

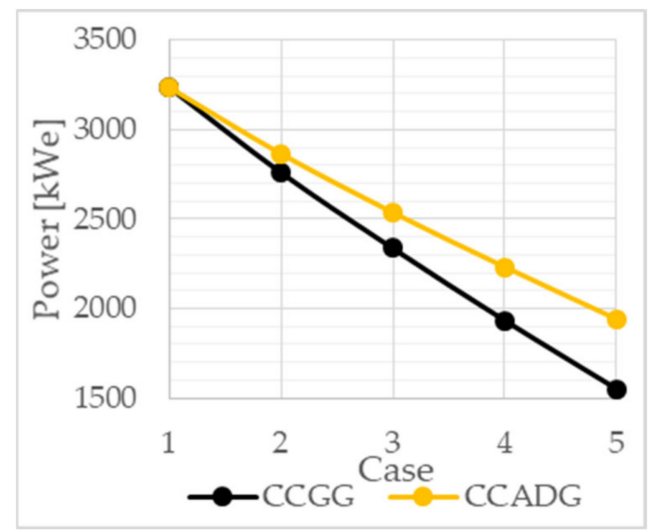

Figure 10. Change of produced power as a function of fuel composition for the considered scenarios with CCGG and CCADG, respectively.

The efficiency of the gas turbine cycle differs significantly in the cases with higher alternative gas content. As shown in Figure 11, with every 10\% increase of the CCGG share in the fuel blend, the efficiency is lower for $\sim 4 \%$ or 0.9 percent points, while for CCADG, the gas turbine plant efficiency decreases $\sim 3 \%$ or 0.7 percent points. The main reason for the lower efficiency value is the lower fuel energy content and the change of the combustion product's density.

Similarly, the supplied heat decreases by increasing the alternative gas content in the fuel mixture, causing a decrease of the combustion products temperature at the end of the combustion chamber. Variation of the temperature at the turbine inlet will cause a decrease of temperature at the turbine outlet, Figure 12. Temperature decreases as a function of fuel composition with lower temperatures for the CCGG scenario, as shown in Figure 12.

One of the analyzed criteria for these alternative gas applications was gas turbine propulsion. Analyses show that the combustion products' flow rates for all cases are at their maximum possible flow rate, Figure 13. 


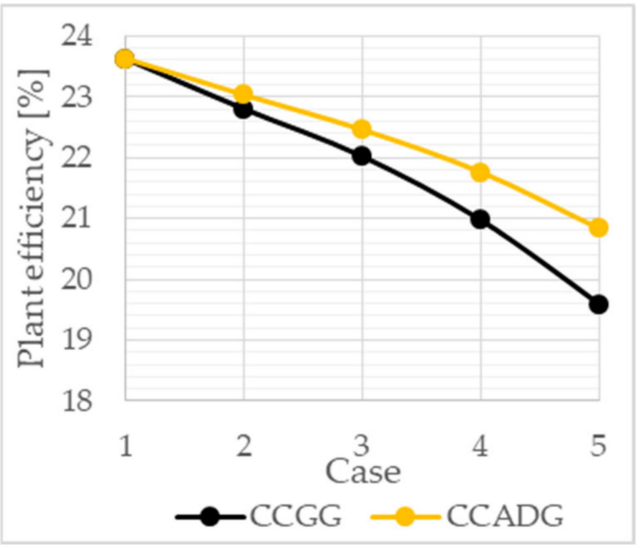

Figure 11. Change of gas turbine plant efficiency as a function of fuel composition for the considered scenarios with CCGG and CCADG, respectively.

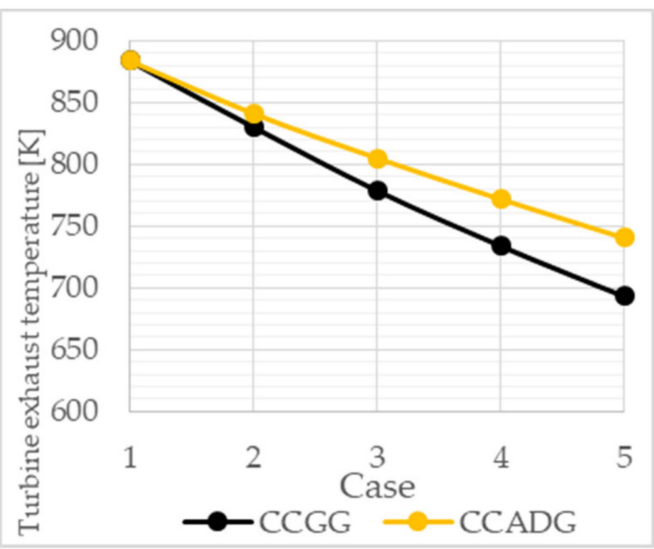

Figure 12. Change of turbine exhaust temperature as a function of fuel composition for the considered scenarios with CCGG and CCADG, respectively.

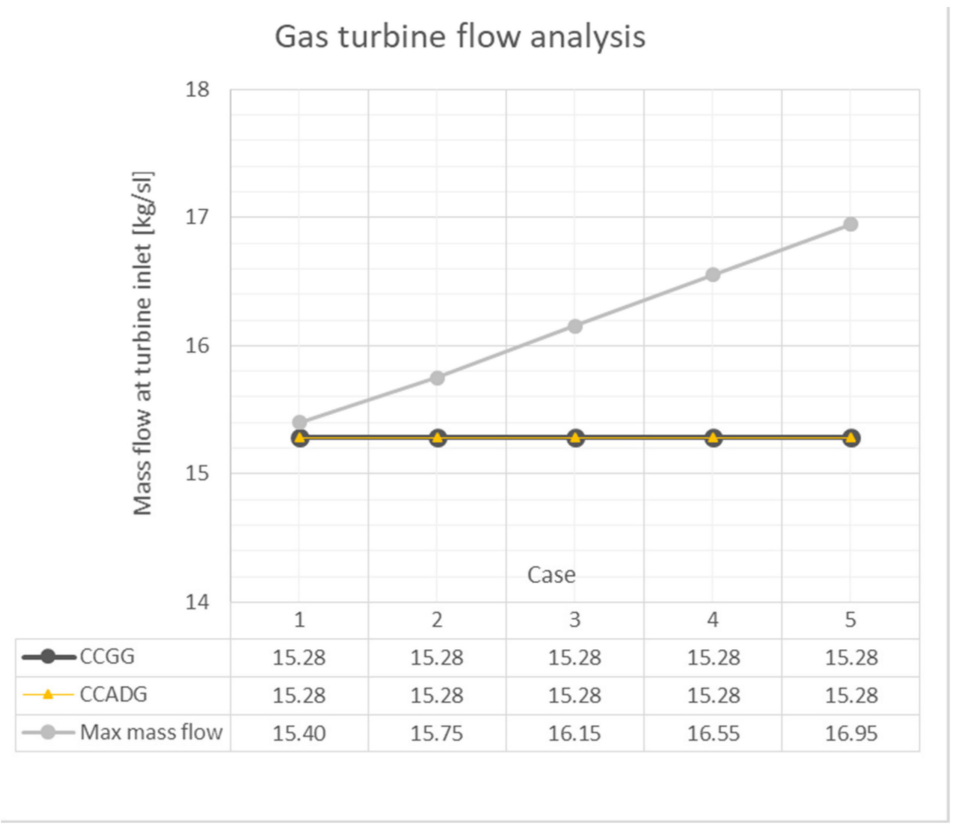

Figure 13. Maximum possible flow rates through the gas turbine, for CCGG and CCADG, respectively, compared to the maximum mass flows through the gas turbine calculated for natural gas. 
Considering the Wobbe Index differences, seen in Figure 14, a standard single manifold fuel system without modifications can be employed for cases 1 and 2 for both CCGG and CCADG, since WI differences are less than 10\% [44]. For cases 3, 4 and 5, WI differences are greater than $10 \%$ and lower than $50 \%$; therefore, it is necessary to modify the fuel system to a dual manifold system [43].

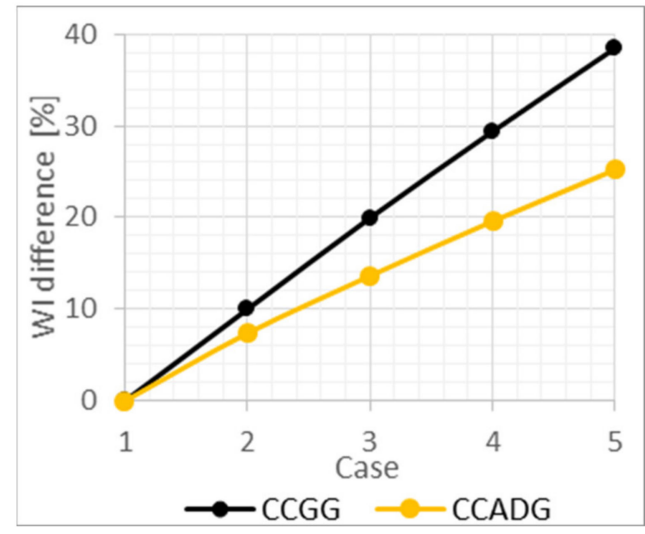

Figure 14. Change of WI difference.

Regarding the fuel propulsion, analyses show that fuel velocity for all cases is at their maximum permissible value of $20 \mathrm{~m} / \mathrm{s}$ [45], Figure 15; therefore, is not necessary to modify the fuel system to separate fuel entries [46].

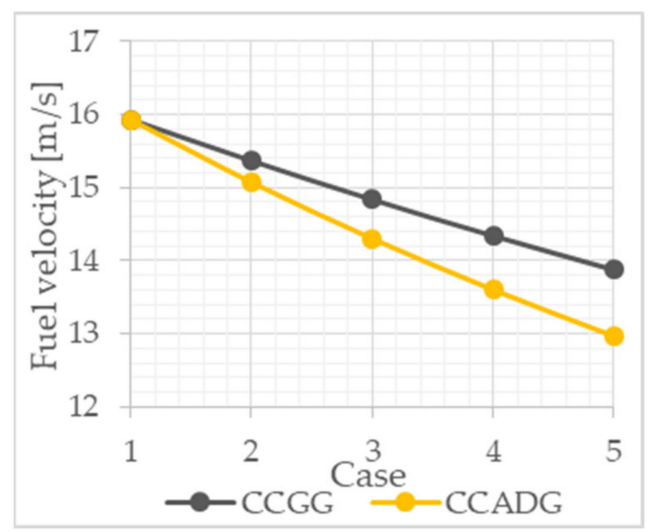

Figure 15. Fuel velocity change.

Overall, results show that conventional fuel systems without any modifications could be applied for cases 1 and 2, in both considered scenarios, while, for cases 3,4 and 5, it is recommended to upgrade the fuel system to a dual manifold system [43].

\subsection{NOx Emissions}

The analysis of the NOx emission has been performed to investigate the effect of fuel composition changes. In this analysis, $\mathrm{NO}$ and $\mathrm{NO}_{2}$ were considered for all five cases of both CCGG and CCADG, from pure natural gas to $40 \%$ alternative gas in the fuel mixture. CHEMKIN-PRO results of the combustion products are presented in Figures 16 and 17. The results show a decrease of both $\mathrm{NO}$ and $\mathrm{NO}_{2}$ values with an increase of alternative gas in the fuel blend. For every $10 \%$ increase of alternative gas in the fuel blend, NO values decrease $~ 75 \%$ with CCGG and about $61 \%$ with CCADG. $\mathrm{NO}_{2}$ values decrease $\sim 61 \%$ with CCGG and about 37\% with CCADG for every $10 \%$ increase of alternative gas share in the fuel blend. Considering the NOx emissions, the corn cob gasification gas has shown significant advantage compared to corn adiabatic digestion gas, especially in those cases of co-firing of fuel blends with higher shares of alternative gas. The phenomenon is 
related to the lower temperatures of combustion, hence lower Zeldovich NO emissions. Simultaneously, the reduced oxygen content leads to lower $\mathrm{NO}_{2}$ for the CCG gas, whereas the CADG blend produces a higher concentration, which is linked to the presence of higher fuel oxygen in the blend that post-reacts with $\mathrm{NO}$ formed at the flame front.

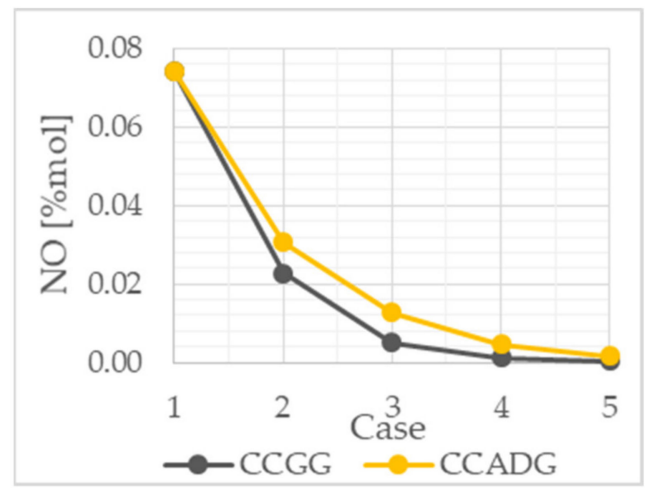

Figure 16. Change of NO.

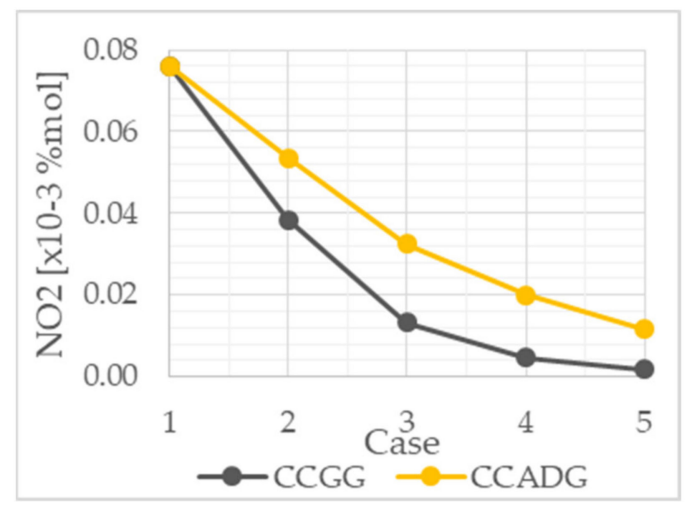

Figure 17. Change of $\mathrm{NO}_{2}$.

\section{Conclusions}

The present concept investigates possibilities of practical implementation of gases that originate from biomass. The main advantage of biomass gas implementation in conventional energy production systems is tangible via the substitution of fossil fuels by alternative fuels. For this analysis, corn cob gasification gas and corn adiabatic digestion gas were investigated to determine the impacts of the fuel quality on a conventional gas turbine cycle. The analyzed alternative gases cannot be implemented in a gas turbine plant by themselves. Therefore, for the implementation of the analyzed alternative gases co-firing with natural gas is required. Two scenarios were numerically simulated: the implementation of corn cob gasification gas and corn adiabatic digestion gas. Various fuel mixtures with different alternative gas ratios were analyzed. Reaction modeling results show a lower value of the adiabatic temperature: $7 \%$ per 10\% CCGG share and $5 \%$ per $10 \%$ CCADG. The amount of the $\mathrm{O}_{2}$ and $\mathrm{N}_{2}$ is higher, while water vapor and $\mathrm{CO}_{2}$ are lower with the addition of the alternative gas in the fuel mixture of both scenarios. The results also show that the analyzed parameters of power, temperature, heat and efficiency are significantly lower with the higher amounts of alternative gas in the fuel mixture, with better potential when using CCADG. In addition, cases with $10 \%$ alternative gas share can operate with conventional fuel systems designed for natural gas. On the other hand, alternative gas shares of $20 \%$ to $40 \%$ require a dual manifold system. Finally, NOx emissions tend to decrease tenfold as the share of biogas increases. Further analyses should be performed to increase the share of corn adiabatic digestion gas in the fuel mixture up to the possible $70 \%$ according to the Wobbe index differences. Therefore, the obtained results 
for CCADG are of great value for agricultural regions such as Serbia with great potential for adiabatic digestion gas production and implementation of the CCADG in electricity production in gas turbine facilities.

Author Contributions: M.G.B. and A.V.-M. entirely conceptualized, investigated, analyzed, wrote and produced this work. All authors have read and agreed to the published version of the manuscript.

Funding: This research received no external funding.

Acknowledgments: This work is done within the project entitled "The Development of a CHP Demonstration Plant with Biomass Gasification“ (Project No. 33049), partially financed by the Ministry of Education, Science and Technological Development of the Republic of Serbia and within the project entitled "Design and development of the anaerobic digestion facilities for production of the biogas from agricultural biomass waste in province Vojvodina Serbia," financed by TERMOINZINJERING d.o.o. Serbia.

Conflicts of Interest: The authors declare no conflict of interest.

\section{References}

1. Jankes, G. Biomass gasification-annual report. Fac. Tech. Sci. Mech. Fac. 2009.

2. Moharamian, A.; Soltani, S.; Rosen, M.A.; Mahmoudi, S.M.S.; Morosuk, T. A comparative thermoeconomic evaluation of three biomass and biomass-natural gas fired combined cycles using organic Rankine cycles. J. Clean. Prod. 2017, 161, 524-544. [CrossRef]

3. Mondal, P.; Ghosh, S. Exergo-economic analysis of a 1-MW biomass-based combined cycle plant with externally fired gas turbine cycle and supercritical organic Rankine cycle. Clean Technol. Environ. Policy 2017, 19, 1475-1486. [CrossRef]

4. Guteša, M.M.; Gvozdenac-Urošević, B.D.; Grković, V.R. Energy and economic effects of CHP with combined technologies of corn cobs gasification and gas turbines. Therm. Sci. 2016, 20, 343-354. [CrossRef]

5. Bazooya, B.; Darabkhani, H.G. Design procedure and performance analysis of a microturbine combustor working on biogas for power generation. In Proceedings of the ASME Turbo Expo 2019: Turbomachinery Technical Conference and Exposition, Phoenix, AZ, USA, 17-21 June 2019. Code 154121.

6. Neilson, C.E. LM2500 Gas Turbine Modifications for Biomass Fuel Operation. Biomass Bioenergy 2010, 15, 269-273. [CrossRef]

7. Franco, A.; Giannini, N. Perspectives for the use of biomass as fuel in combined cycle power plants. Int. J. Therm. Sci. 2005, 44, 163-177. [CrossRef]

8. Datta, A.; Mondal, S.; Gupta, S.D. Perspectives for the direct firing of biomass as a supplementary fuel in combined cycle power plants. Int. J. Energy Resour. 2008, 32, 1241-1257. [CrossRef]

9. Bhattacharya, A.; Manna, D.; Paul, B.; Datta, A. Biomass integrated gasification combined cycle power generation with supplementary biomass firing: Energy and exergy-based performance analysis. Energy 2011, 36, 2599-2610. [CrossRef]

10. Kang, D.W.; Kim, T.S.; Hur, K.B.; Park, J.K. The effect of firing biogas on the performance and operating characteristics of simple and recuperative cycle gas turbine combined heat and power systems. Appl. Energy 2012, 93, 215-228. [CrossRef]

11. Adouane, B.; Hoppesteyn, P.; de Jong, W.; van der Wel, M.; Hein, K.R.G.; Spielthoff, H. Gas turbine combustor for biomass derived LCV gas, a first approach towards fuel-NOx modelling and experimental validation. Appl. Therm. Eng. 2002, 22, 959-970. [CrossRef]

12. Guteša Božo, M.; Valera-Medina, A.; Syred, N.; Bowen, P.J. Fuel quality impact analysis for practical implementation of corn cob gasification gas in conventional gas turbine power plants. Biomass Bioenergy 2019, 122, 221-230. [CrossRef]

13. Sansaniwala, S.K.; Pala, K.; Rosenb, M.A.; Tyagia, S.K. Recent advances in the development of biomass gasification technology: A comprehensive review. Renew. Sustain. Energy Rev. 2017, 72, 363-384. [CrossRef]

14. Guteša Božo, M.; Guteša, M. Design and Development of the Anaerobic Digestion Facilities for Production of the Biogas from Agricultural Biomass Waste in Province Vojvodina Serbia; Internal Company Data from Project Documentation; Termoinzinjering, D.O.O.: Novi Sad, Serbia, 2021.

15. Vindis, P.; Mursec, B.; Janzekovic, M.; Stajnko, D.; Cus, F. Anaerobic digestion of maize hybrids for methane production. J. Achiev. Mater. Manuf. Eng. 2010, 40, 87-94.

16. Walter, A.; Llagostera, J. Feasibility analysis of co-fired combined-cycles using biomass-derived gas and natural gas. Energy Convers. Manag. 2007, 48, 2888-2896. [CrossRef]

17. Liu, K.; Sanderson, V. The influence of changes in fuel calorific value to combustion performance for Siemens SGT-300 dry low emission combustion system. Fuel 2013, 103, 239-246. [CrossRef]

18. Bharathirajaa, B.; Sudharsanaa, T.; Jayamuthunagaib, J.; Praveenkumarc, R.; Chozhavendhand, S.; Iyyappana, J. Biogas production-A review on composition, fuel properties, feed stock and principles of anaerobic digestion. Renew. Sustain. Energy Rev. 2018, 90, 570-582. [CrossRef]

19. Van Foreest, F. Perspectives for Biogas in Europe; Oxford Institute for Energy Studies: Oxford, UK, 2012.

20. Nishio, N.; Nakashimada, Y. Recent development of anaerobic digestion processes for energy recovery from wastes. J. Biosci. Bioeng. 2007, 103, 105-112. [CrossRef] [PubMed] 
21. Caposciutti, G.; Baccioli, A.; Ferrari, L.; Desideri, U. Impact of ambient temperature on the effectiveness of inlet air cooling in a co-digestion biogas plant equipped with a mGT. Energy Convers. Manag. 2020, 216, 112874. [CrossRef]

22. Zare, A.; Saray, R.K.; Mirmasoumi, S.; Bahlouli, K. Optimization strategies for mixing ratio of biogas and natural gas co-firing in a cogeneration of heat and power cycle. Energy 2019, 181, 635-644. [CrossRef]

23. Amiri Rad, E.; Kazemiani-Najafabadi, P. Introducing a novel optimized Dual Fuel Gas Turbine (DFGT) based on a 4E objective function. J. Clean. Prod. 2019, 206, 944-954. [CrossRef]

24. Flores, R.; Brouwer, J. Optimizing natural gas combined cycle part load operation. In Proceedings of the ASME 2019 Power Conference, POWER 2019, Salt Lake City, UT, USA, 15-18 July 2019. Code 155466.

25. Darabadi Zareh, A.; Khoshbakhti Saray, R.; Mirmasoumi, S.; Bahlouli, K. Extensive thermodynamic and economic analysis of the cogeneration of heat and power system fueled by the blend of natural gas and biogas. Energy Convers. Manag. 2018, 164, 329-343. [CrossRef]

26. Hoda, A.; Rahman, T.M.R.; Asrar, W.; Khan, A.K. A Comparative Study of Natural Gas and Biogas Combustion in A Swirling Flow Gas Turbine Combustor. Combust. Sci. Technol. 2021, 1-28. [CrossRef]

27. Somehsaraei, H.N.; Majoumerd, M.M.; Assadi, M. Performance assessment of a micro gas turbine cycle with exhaust gas recirculation fueled by biogas for post-combustion carbon capture application. In Proceedings of the ASME Turbo Expo 2018: Turbomachinery Technical Conference and Exposition, GT 2018, Oslo, Norway, 11-15 June 2018. Code 138886.

28. Mohammadpour, M.; Houshfar, E.; Ashjaee, M.; Mohammadpour, A. Energy and exergy analysis of biogas fired regenerative gas turbine cycle with $\mathrm{CO}_{2}$ recirculation for oxy-fuel combustion power generation. Energy 2021, 220, 119687. [CrossRef]

29. Jenifer, L.; Annie Elisabeth Jebaseeli, E. Anaerobic digestion based modeling and simulation of bio gas fuel system. J. Green Eng. 2020, 10, 1-12.

30. Al-Rasheda, A.A.A.A.; Masoud, A. Multi-criteria exergoeconomic optimization for a combined gas turbine-supercritical $\mathrm{CO}_{2}$ plant with compressor intake cooling fueled by biogas from anaerobic digestion. Energy 2021, 223, 119997. [CrossRef]

31. Guteša, M.; Al-Doboon, A.; Valera-Medina, A.; Syred, N.; Bowen, P. CARSOXY ( $\mathrm{CO}_{2}$-Argon-Steam-OxyFuel) Combustion in Gas Turbines for CCS Systems. In Proceedings of the 55th AIAA Aerospace Sciences Meeting, Grapevine, TX, USA, 9-13 January 2017. [CrossRef]

32. Al-Doboon, A.; Guteša, M.; Valera-Medina, A.; Syred, N.; Ng, J.-H.; Chong, C.T. CO 2 -argon-steam oxy-fuel (CARSOXY) combustion for CCS inert gas atmospheres in gas turbines. Appl. Therm. Eng. 2017, 122, 350-358. [CrossRef]

33. Müller, K.J. Grundzüge der Thermischen Turbomaschinen, Vorlesung Turbomaschinen und Energieanlagen; Institut für Thermische Turbomaschinen und Energieanlagen, Universität Wien: Vienna, Austria, 1991.

34. Guteša, M. The Numerical Simulation Model of Gas Turbine Facility for Biomass Gasification Gas Application. Ph.D. Thesis, University of Novi Sad, Faculty of Technical Sciences, Novi Sad, Serbia, 2017. (In Serbian).

35. Shmakov, A.G.; Korobeinichev, O.P.; Rybitskaya, I.V.; Cherno, A.A.; Knyazko, D.A.; Bolshova, T.A.; Konnov, A.A. Formation and consumption of $\mathrm{NO}$ in $\mathrm{H}_{2}+\mathrm{O}_{2}+\mathrm{N}_{2}$ flames doped with $\mathrm{NO}$ or $\mathrm{NH}_{3}$ at atmospheric pressure. Combust. Flame 2010, 157, 556-565. [CrossRef]

36. Duynslaegher, C.; Jeanmart, H.; Vandooren, J. Ammonia Combustion at Elevated Pressure and Temperature Conditions. Fuel 2010, 89, 3540-3545. [CrossRef]

37. Duynslaegher, C.; Contino, F.; Vandooren, J.; Jeanmart, H. Modelling Ammonia Combustion at Low Pressure. Combust. Flame 2012, 159, 2799-2805. [CrossRef]

38. Rutar, T.; Malte, P.C. NOx Formation in High-Pressure Jet-Stirred Reactors with Significance to Lean-Premixed Combustion Turbines. J. Eng. Gas Turbines Power 2002, 124, 776-783. [CrossRef]

39. Syred, N. A review of oscillation mechanisms and the role of the processing vortex core (PVC) in Swirl Combustion systems. Prog. Energy Combust. Sci. 2006, 32, 93-161. [CrossRef]

40. Valera-Medina, A.; Syred, N.; Bowen, P. Central recirculation zone visualization in confined swirl combustors for terrestrial energy. J. Propuls. Power 2013, 29, 195-204. [CrossRef]

41. Valera-Medina, A.; Marsh, R.; Runyon, J.; Pugh, D.; Beasley, P.; Hughes, T.; Bowen, P. Ammonia-methane combustion in tangential swirl burners for gas turbine power generation. Appl. Energy 2016, 185, 1362-1371. [CrossRef]

42. Reaction Design. CHEMKIN Tutorials Manual CHEMKIN®Software.10112/15112; Reaction Design: Livermore, CA, USA, 2011; pp. 1-274.

43. Rowen, W.I. Design Considerations for Gas Turbine Fuel Systems; GE Company: Schenectady, NY, USA, 1991; Volume 28, pp. 1-17.

44. Meier, G.J.; Hung, W.S.Y.; Sood, V.M. Development and Application of Industrial Gas Turbines for Medium-Btu Gaseous Fuels. J. Eng. Gas Turbines Power 1986, 108, 182-190. [CrossRef]

45. Strelec, V. Dokumentacija Izvanrednih Izdanja Transfera Tehnologije; Interprogres: Zagreb, Croatia, 1980.

46. Chacartegui, R.; Sánchez, D.; Muñoz de Escalona, J.M.; Muñoz, A.; Sánchez, T. Gas and steam combined cycles for low calorific syngas fuels utilization. Appl. Energy 2013, 101, 81-92. [CrossRef] 